\title{
Journal of Applied Electrochemistry
}

Fabrizio Vicari ${ }^{\mathrm{a}}$, Adriana D’Angelo ${ }^{\mathrm{a}}$, Yohan Kouko ${ }^{\mathrm{b}}$, Alessandro Loffredi ${ }^{\mathrm{a}}$, Alessandro Galia ${ }^{\mathrm{a}}$, Onofrio Scialdone ${ }^{\mathrm{a}^{*}}$

aDepartment of Innovation, Industrial and Digital (DIID, Ingegneria Chimica, Gestionale, Informatica, Meccanica), Università degli Studi di Palermo, 90128 Palermo, Italy.

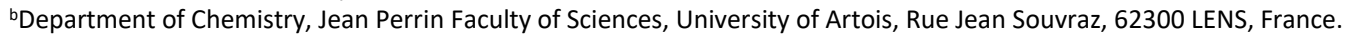

*corresponding authors: onofrio.scialdone@unipa.it, +39 09123863754

In the past few years, thermally regenerative ammonia battery (TRAB) has been proposed as an effective tool to recover waste heat at temperatures below $130{ }^{\circ} \mathrm{C}$. Most of the literature available is devoted to the power production step, with less attention being given to the regeneration step (e.g. the removal of ammonia from the anolyte). In this paper, the TRAB is analyzed with particular attention to the regeneration step and to the study of various generation of energy-regeneration cycles. It was shown that approximately $90^{\circ} \mathrm{C}$ is necessary for the regeneration step due to the fact that ammonia is present in the anolyte mainly as an ammonia complex. Various cycles were performed with success, demonstrating the efficacy of the proposed regeneration step.

\section{Introduction}

22 Global energy demand and resources reclamation, have recorded an unpredictable growth in the past decades, with consequences that are yet to be completely understood [1,2]. While an ideal target is to substitute every non-renewable source with a renewable alternative, a more urgent topic is the global need for increased energy efficiency in a short period of time. With the term waste heat, all the forms of 
27 the available technology are grouped. In recent work, a preliminary calculation computed a significant

28 amount of potential energy, 370.41 TWh, wasted annually in Europe in the industrial sector alone [4].

29 Additional energy is contained in the waste heat coming from the sun, the earth or internal combustion

30 engines. Many researchers are currently working on different strategies to use these forms of energy,

31 among which thermally regenerative electrochemical cycle (TREC) is currently regarded as a promising

32 approach due to its relatively high theoretical efficiency [3]. While the original intention of TREC was to

33 harvest high temperature energy for nuclear or aerospace systems $\left(T>500{ }^{\circ} \mathrm{C}\right)$ [5], a Thermally

34 Regenerative Ammonia Battery (TRAB) has recently been developed for the application range below 130

$35{ }^{\circ} \mathrm{C}[6]$. A TRAB consists of two identical sealed compartments housing two copper electrodes separated

36 by an Anion Exchange Membrane [6], both compartments are alternately operated as anodic or cathodic

37 in successive cycles. The presence of ammonia characterizes the anolyte, which gives rise to an electrode

38 potential dependent on the complexation of the copper electrode according to the following reaction (eq.

39 1), while at the cathode, the reaction is the cathodic deposition of copper (eq. 2) [6]:

$40 \mathrm{Cu}_{(\mathrm{s})}+4 \mathrm{NH}_{3(\mathrm{aq})} \rightarrow \mathrm{Cu}\left(\mathrm{NH}_{3}\right)_{4}{ }^{2+}{ }_{(\mathrm{aq})}+2 \mathrm{e}^{-} \quad\left(E^{0}=-0.04 \mathrm{~V}\right.$ vs SHE $)$

$41 \mathrm{Cu}^{2+}{ }_{\text {(aq) }}+2 \mathrm{e}^{-} \rightarrow \mathrm{Cu}_{(\mathrm{s})} \quad\left(E^{0}=+0.34 \mathrm{~V}\right.$ vs SHE $)$

42 At the end of one cycle, the complex-saturated anolyte requires regeneration in a distillation column in

43 order to regain the ammonia; this ammonia is added to the spent (poor in copper) catholyte, to obtain

44 the new anolyte. In this closed-loop cycle, the cathodic chamber is converted into the new anodic chamber

45 with the same concept applying to the other compartment [6]. The Carnot-based efficiency of this cycle

46 was estimated to be just 13\% [7], a fraction that cannot be realistically regarded as an answer to the global

47 energy demand. Additionally, in order to be qualified as a real cyclic process, TRAB needs to overcome

48 two major limitations: 
i. The unbalanced anodic and cathodic efficiency, mainly due to a reduced anodic current efficiency [8];

51 ii. The lack for systematic studies of the regeneration phase.

52 While it seems that the first limitation can be overcome using metals other than copper (e.g. silver) [9], a 53 study focused on the waste heat exploitation in this context is yet to be explored. It was reported that a 54 temperature of $60^{\circ} \mathrm{C}$ could sustain the almost complete (97\%) ammonia vaporization in a 0.1 atm vacuum 55 distillation [6] whereas, when the temperature effect on power generation was assessed using 10 hour 56 long TRAB tests, temperatures as high as $72^{\circ} \mathrm{C}$ were employed [7]. Furthermore, the addition of acid was 57 reported to be necessary during regeneration by simple heating due to the formation of $\mathrm{Cu}(\mathrm{OH})_{2}$, other 58 operating parameters used for regeneration were not given [6].

59 Adopting different reactor geometry, ammonia flow battery (AFB) was constructed on the base of the 60 TRAB, resulting in a compact stack for continuous energy production at higher voltages [10]. However, 61 fresh anolyte and catholyte were used in every cycle as an alternative to regenerating the solution [10].

62 Despite the further improvements that were acquired in power production using different separators [11], 63 other ligands [8], or electrodes [9], less attention was devoted to the regeneration step. None of these 64 studies have unveiled the details of the regeneration, which is as important as the energy production 65 phase in a waste-heat energy recovery framework.

66 Hence, in this paper the TRAB process was studied with regards to the energy production step, 67 regeneration step and energy production through successive regenerations. Particular attention was 68 given to regeneration since the applicability of the method could be limited by an ineffective regeneration 69 process. 


\section{$71 \quad 2.1$ Cell assembly and operation}

72 The reactor adopted for the TRAB was very similar to the one used in [6], briefly, the anode and cathode

73 chambers were cylinders of $3 \mathrm{~cm}$ in diameter and $4 \mathrm{~cm}$ in length made of Plexiglas. The two chambers had

74 a sampling port, a current collector hole and reference electrode housing (see supporting information,

75 figure S1). A saturated calomel electrode (SCE, +0.241 vs NHE) was used. The two chambers were screwed

76 together, separated by a $7 \mathrm{~cm}^{2}$ AEM (Selemion AMV, Asashi glass, Japan). Flat copper electrodes were

77 used with a projected surface of $2 \times 0.8 \mathrm{~cm}^{2}$, current was collected with copper sticks, while wires were

78 the external circuit. Both anode and cathode chambers were stirred using a magnetic bar of $6.5 \mathrm{~mm}$ in

79 diameter and $16 \mathrm{~mm}$ in length (Sigma-Aldrich). De-ionized (DI) water and Sigma Aldrich reagents were

80 used for all the experiments. Both the anolyte and catholyte contained $\mathrm{NH}_{4}\left(\mathrm{NO}_{3}\right) 5 \mathrm{M}$ and $\mathrm{Cu}\left(\mathrm{NO}_{3}\right)_{2} 0.1 \mathrm{M}$

81 unless stated differently. The anolyte also included ammonia in the form of ammonium hydroxide

$82\left(\mathrm{NH}_{4} \mathrm{OH}\right) 2 \mathrm{M}$ which was consistent for all tests excluding when the effect of its concentration was assessed.

83 Sodium hydroxide $(\mathrm{NaOH}) 0.45 \mathrm{M}$, was also added to the anolyte for some specific experiments.

\subsection{Calculations and measurements}

85 During polarization, cell $\left(E_{\text {cell }}\right)$ and electrode $(E)$ potentials were measured with a conventional multimeter

86 (mod. 5400, ICE, Italy), while a model 2700 (Keithley) data-logger was used during power generation

87 measurements, recording a value at each minute. Polarization tests were performed analogically, varying

88 the external resistance from $1 \Omega$ to $200 \Omega$ at fixed five-minute intervals. Current and power densities were

89 calculated using the project surface of one electrode or the volume of solution contained in both

90 compartments (60 mL). Anodic coulombic efficiency (ACE) was calculated as follows (eq. 3):

$91 \quad A C E(\%)=\frac{Q \cdot M W_{C u}}{2 F} \cdot \frac{1}{\left(m_{0, a}-m_{f, a}\right)} \cdot 100$ 
92 where $Q$ is the total charge passed through the external circuit, calculated as the integral of the current $I$

93 in time, $M W_{c u}$ is the molar weight of copper, $F$ is the Faraday constant $\left(96485 \mathrm{C} \mathrm{mol}^{-1}\right)$ and $m_{0, \mathrm{a}}$ and $m_{f, \mathrm{a}}$

94 are the initial and final weight of the electrodes, respectively. As the main scope of this work was to test

95 the possibility to recover ammonia used in the TRAB process, a calibration curve was obtained using

96 eleven different solutions at different ammonia complex concentrations. The eleven solutions were

97 prepared three times with ammonia nitrate 5M present in all the solutions. The UV-VIS absorbance at the

98 emission-spectrum peak, which was found to be dependent on composition, and pH were measured (Cary

9960 UV-VIS spectrophotometer, Agilent, US and HI $98130 \mathrm{pH} /$ conductivity meter, Hanna instruments, Italy).

100 The average values obtained from these characterizations were used as reference parameters for

101 concentration estimation through an exponential fitting. There is a complete agreement between the two

102 relations, seen in table 1 , but the calibration curve obtained with reference to $\mathrm{pH}$ was used, due to its

103 higher repeatability.

\begin{tabular}{|c|c|c|c|c|c|c|c|}
\hline Solution & $\begin{array}{c}\mathrm{Cu}\left(\mathrm{NO}_{3}\right)_{2} \\
{[\mathrm{M}]}\end{array}$ & $\begin{array}{c}\mathrm{NH}_{4} \mathrm{NO}_{3} \\
{[\mathrm{M}]}\end{array}$ & $\begin{array}{l}\mathrm{NH}_{3} \\
{[\mathrm{M}]}\end{array}$ & $\begin{array}{c}\mathrm{pH}_{\text {Avg }} \\
\pm \text { stnd. dev. }\end{array}$ & $\begin{array}{c}\lambda_{\text {Peak,Avg }} \\
{[\mathrm{nm}]}\end{array}$ & $\begin{array}{c}\text { Abs Avg } \\
\pm \text { stnd. dev. }\end{array}$ & $\begin{array}{c}\mathrm{Cu}[\mathrm{NH} 3]_{4}{ }^{2+} \\
{[\mathrm{M}]}\end{array}$ \\
\hline 1 & \multirow{11}{*}{0.75} & \multirow{11}{*}{5} & \multirow{10}{*}{ 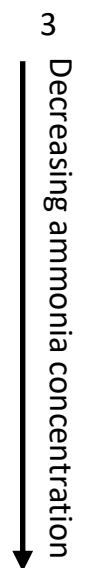 } & $10.20 \pm 0.10$ & 621 & $2.12 \pm 0.53$ & 0.75 \\
\hline 2 & & & & $10.09 \pm 0.16$ & 616 & $1.97 \pm 0.48$ & 0.68 \\
\hline 3 & & & & $10.01 \pm 0.13$ & 607 & $1.89 \pm 0.48$ & 0.60 \\
\hline 4 & & & & $9.94 \pm 0.11$ & 604 & $1.77 \pm 0.45$ & 0.53 \\
\hline 5 & & & & $9.93 \pm 0.06$ & 601 & $1.69 \pm 0.43$ & 0.45 \\
\hline 6 & & & & $9.68 \pm 0.11$ & 599 & $1.60 \pm 0.41$ & 0.38 \\
\hline 7 & & & & $9.61 \pm 0.14$ & 601 & $1.54 \pm 0.39$ & 0.30 \\
\hline 8 & & & & $9.36 \pm 0.13$ & 592 & $1.44 \pm 0.40$ & 0.23 \\
\hline 9 & & & & $9.05 \pm 0.10$ & 596 & $1.27 \pm 0.36$ & 0.15 \\
\hline 10 & & & & $7.09 \pm 0.15$ & 617 & $1.00 \pm 0.30$ & 0.08 \\
\hline 11 & & & 0 & $2.68 \pm 0.14$ & 809 & $0.36 \pm 0.02$ & 0.00 \\
\hline
\end{tabular}

Table 1: Reference solutions used for the quantification of copper-ammine complex saturation-degree. $\lambda_{\text {Peak,Avg }}$ : average wavelength of the absorbance peak in the UV-VIS spectrum. AbS Avg $=A_{\text {Abs }}$ Avg $\left(\lambda_{\text {Peak,Avg }}\right)$ : Absorbance at the peak of the UV-VIS spectrum. 
105 Regeneration was accomplished by adopting a simple apparatus for distillation (see supporting 106 information, figure S2). A $0.1 \mathrm{~L}$ balloon or column was submerged into a thermostatic water bath at

107 various temperatures (mainly $60^{\circ} \mathrm{C}, 90^{\circ} \mathrm{C}$ and $100^{\circ} \mathrm{C}$ ). A sub-horizontal, insulated glass pipe was used to 108 collect the vapors, which led into a coaxial, vertically placed heat exchanger. The heat exchanger jacket 109 had a continuous flow of tap water at $20^{\circ} \mathrm{C}$. Finally, a collecting flask was placed at the end of the 110 exchanger, submerged into an ice bath, to ensure condensation occurred. Initially, the outlet of the final 111 flask was left open to the atmosphere; this method was changed by connecting the outlet to a vacuum 112 pump operating at 0.1 bar for the remainder of the experiments. When the vacuum pump was used, the 113 heating column was equipped with a glass pipe, $0.35 \mathrm{~cm}$ in diameter, to allow the passage of an air 114 stripping flow. For some experiments, nitric acid (69\% $\mathrm{HNO}_{3}$, Sigma-Aldrich) was also added to the solution 115 to be regenerated in order to assess its influence on the efficiency of the process.

\subsection{Preliminary experiments on power generation}

119 Preliminary experiments were performed in order to study the effect of some parameters on the 120 generation of energy, and to define the operating conditions to be used for entire cycles (generation of 121 energy + regeneration).

\subsubsection{Effect of stirring rate}

123 It was shown that, in TRAB systems, power production can be affected by ammonia concentration 124 polarization at the cathode [6], for this reason, an adequate stirring rate could result in higher power 125 densities. Nevertheless, an assessment of the influence of such a parameter was not provided and a single 
value $(600 \mathrm{rpm})$ was often used $[7,8,11,12]$. Hence, the effect of three different stirring rates on power

127 density was compared in figure 1, the results highlight that the energy production from TRAB may be 128 enhanced by an adequate mass transfer as in the absence of stirring, the power produced was $30.1 \mathrm{~W} \mathrm{~m}^{-}$

1292 , compared to $37.6 \mathrm{~W} \mathrm{~m}^{-2}$ at the highest rate of $700 \mathrm{rpm}$. These results are also in line with literature 130 regarding to AFB [10], where the maximum power density of $45 \mathrm{~W} \mathrm{~m}^{-2}$ was obtained at $4 \mathrm{~mL} \mathrm{~min}^{-1}$.

\subsubsection{Effect of ammonia and copper nitrate concentration}

133 It was already shown that an increase of the concentration of ammonia in the anodic solution can 134 drastically influence the power density produced. From the TRAB research conducted by the Penn State 135 University research group, increasing $\mathrm{NH}_{3}$ concentration from $1 \mathrm{M}$ to $3 \mathrm{M}$ allowed a considerable increase 136 in power density [6]. In the present paper, the range examined in that work was extended, adopting the 137 same operative parameters (i.e. stirring rate of $500 \mathrm{rpm}$ ) and testing the effect of ammonia concentration 138 from $0.5 \mathrm{M}$ to $4 \mathrm{M}$ (Table 2). These findings also indicated that increasing ammonia concentration from $1390.5 \mathrm{M}$ to $2 \mathrm{M}$ was beneficial to the power output process, however, when the concentration was further 140 increased up to $4 \mathrm{M}$, power density decreased to $29.40 \mathrm{~W} \mathrm{~m}^{-2}$ (see Table 2). This result is in agreement 141 with AFB data as power density decreased from 36 to $34 \mathrm{~W} \mathrm{~m}^{-2}$ when the ammonia concentration 142 increased from $3 \mathrm{M}$ to $4 \mathrm{M}[10]$. It can be noted that AFB power densities were close to the findings shown 143 in the present paper [6]. In table 2, the anodic coulombic efficiency also depended on the ammonia 144 concentration and the maximum value was obtained at $2 \mathrm{M}$. Increasing ammonia concentration shifts the $145 \mathrm{pH}$ of the anodic solution toward higher $\mathrm{pH}$, which ends up affecting the equilibrium of the solution. As 146 discussed in [13], when $\mathrm{pH}$ is raised over 12 the more abundant form of copper becomes $\mathrm{CuO}_{(\mathrm{s})}$, which 147 precipitates affecting the performance of the TRAB process. 


\begin{tabular}{|c|c|c|c|}
\hline $\begin{array}{l}\mathrm{NH}_{3} \\
\text { (M) }\end{array}$ & $\begin{array}{c}j \\
\left(A^{-2}\right)^{-2}\end{array}$ & $\begin{array}{c}p(j) \\
\left(W m^{-2}\right)\end{array}$ & $\begin{array}{l}A C E \\
(\%)\end{array}$ \\
\hline 0.5 & 76.8 & 11.1 & 23 \\
\hline 1 & 117.5 & 21.6 & 35 \\
\hline 2 & 129.3 & 31.3 & 49 \\
\hline 4 & 116.2 & 29.4 & 45 \\
\hline \multicolumn{4}{|c|}{$\begin{array}{l}\text { Table 2: Effect of ammonia concentration on the maximum } \\
\text { power density }(p) \text { and Anodic Coulombic Efficiency (ACE) } \\
\text { recorded at a given current density (j) during polarization. } \\
\mathrm{NH}_{4}\left(\mathrm{NO}_{3}\right)_{5} 5 \mathrm{M} \text { and } \mathrm{Cu}\left(\mathrm{NO}_{3}\right)_{2} \mathrm{O} 0.1 \mathrm{M} \text { were used for both anodic } \\
\text { and cathodic solutions. Stirring rate: } 500 \mathrm{rpm} \text {. }\end{array}$} \\
\hline
\end{tabular}

149 The effect of copper nitrate concentration on power density was assessed in the range of $0.03 \mathrm{M}$ to 0.2

$150 M$, extending and adding intermediate values to those explored in [6]. One of the additional points studied

151 was $0.15 \mathrm{M}$ that accounted for $31.56 \mathrm{~W} \mathrm{~m}^{-2}$ (see Table 3), slightly above the $31.33 \mathrm{~W} \mathrm{~m}^{-2}$ and the $27.01 \mathrm{~W}$

$152 \mathrm{~m}^{-2}$ obtained with $0.1 \mathrm{M}$ and $0.2 \mathrm{M}$ concentrations of $\mathrm{Cu}\left(\mathrm{NO}_{3}\right)_{2}$ respectively. However, the highest anodic 153 coulombic efficiency was obtained for $0.1 \mathrm{M} \mathrm{Cu}\left(\mathrm{NO}_{3}\right)_{2}$ (Table 3).

\begin{tabular}{|c|c|c|c|}
\hline $\begin{array}{c}\mathrm{Cu}\left(\mathrm{NO}_{3}\right)_{2} \\
\text { (M) }\end{array}$ & $\begin{array}{c}J \\
\left(A^{-2}\right)^{-2}\end{array}$ & $\begin{array}{c}p(j) \\
\left(W m^{-2}\right)\end{array}$ & $\begin{array}{l}A C E \\
(\%)\end{array}$ \\
\hline 0.03 & 74.4 & 16.9 & 34 \\
\hline 0.07 & 86.3 & 22.7 & 32 \\
\hline 0.10 & 129.4 & 31.3 & 49 \\
\hline 0.15 & 141.9 & 31.6 & 38 \\
\hline 0.20 & 131.3 & 27.0 & 34 \\
\hline \multicolumn{4}{|c|}{$\begin{array}{l}\text { Table 3: Effect of copper nitrate concentration on the maximum } \\
\text { power density (p) and Anodic Coulombic Efficiency (ACE) } \\
\text { recorded at a given current density (j) during polarization. } \\
\mathrm{NH}_{4}\left(\mathrm{NO}_{3}\right) 5 \mathrm{M} \text { was used for both anodic and cathodic solutions } \\
\text { and } 2 \mathrm{M} \text { of } \mathrm{NH}_{3} \text { was also added to the anodic solution. Stirring } \\
\text { rate: } 500 \mathrm{rpm} \text {. }\end{array}$} \\
\hline
\end{tabular}

156 This outcome can be attributed to the fact that ammonia reacts with copper nitrate generating the same

157 product of the reaction (1) thus affecting the electrochemical potential of the reaction according to Nernst 158 equation and Le-Chatelier principle. 
161 Vazquez-Arenas, Lazaro and Cruz have studied the electrochemical behavior of copper-ammonia 162 complexes as a function of the $\mathrm{pH}$ [13]. In their studies, ammonia chloride was used in the place of 163 ammonia-nitrate, nevertheless the results obtained can give some indication on predicting TRAB behavior 164 under different scenarios. One relevant finding of the aforementioned work is the complexation form of 165 copper that changes from eq. 1 to the following eq. 4 when $\mathrm{pH}$ is between 9.5 and 12 [13]:

$\mathrm{Cu}_{(\mathrm{s})}+5 \mathrm{NH}_{3(\mathrm{aq})} \rightarrow \mathrm{Cu}\left(\mathrm{NH}_{3}\right)_{5}{ }^{2+}{ }_{(\mathrm{aq})}+2 \mathrm{e}^{-} \quad\left(\mathrm{E}_{0}=-0.0007 \mathrm{~V} \text { vs SHE}\right)^{1}$

167 It was also demonstrated that in this $\mathrm{pH}$ range, the overpotentials related to copper oxidation were 168 reduced [13]. Furthermore, the Gibbs standard free energy related to the formation of the penta169 ammonia complex is higher than that of the tetra complex $\left(-32 \mathrm{vs}-26 \mathrm{Kcal} \mathrm{mol}^{-1}\right)$ [14], making the former 170 likely to be more effective in terms of energy production, which is a condition that could be considered. 171 For this reason, the effect of an increased anodic $\mathrm{pH}$ of 10.5 was assessed during polarization tests through 172 the addition of $0.42 \mathrm{M} \mathrm{NaOH}$ to the standard solution. An increased maximum power density of $35.71 \mathrm{~W}$ $173 \mathrm{~m}^{-2}$ was observed during polarization corresponding to $138.12 \mathrm{~A} \mathrm{~m}^{-2}$, against the $31.33 \mathrm{~W} \mathrm{~m}^{-2}$ recorded 174 with $0.1 \mathrm{M} \mathrm{Cu}\left(\mathrm{NO}_{3}\right)_{2}, 5 \mathrm{M} \mathrm{NH}_{4}\left(\mathrm{NO}_{3}\right)$ and $2 \mathrm{M}$ of $\mathrm{NH}_{3}$ (see fig. 1). Conversely, ACE did not change 175 significantly, recording just $38.5 \%$.

\footnotetext{
${ }^{1}$ Potential calculated on the base of the Gibbs standard free energy obtained by ref. [14]
} 


\subsection{Regeneration of the solutions}

177 According to the results mentioned above, the first part of the study of the regeneration was carried out

178 using synthetic solutions replicating the amount of $\mathrm{Cu}(\mathrm{NH} 3)_{4}{ }^{2+}$ that can be found at the end of a 179 polarization cycle (about $0.3 \mathrm{M}$ ). Then, actual residual solutions from a continuous system were treated, 180 characterized by low complex concentration.

\subsubsection{Effect of the temperature}

182 The first regeneration experiments were carried out for $4 \mathrm{~h}$ at both $60{ }^{\circ} \mathrm{C}$ and $100{ }^{\circ} \mathrm{C}$ with an initial 183 concentration of the ammonia complex at approximately $0.31 \mathrm{M}$. According to the literature, a 184 temperature as low as $50^{\circ} \mathrm{C}$ could allow the distillation of the saturated anolyte solution [6]. However, as 185 shown in fig. 2 , at $60^{\circ} \mathrm{C}$ after $4 \mathrm{~h}$, a minimum of $0.1 \mathrm{M}$ of ammonia was still present in water. The utilization 186 of a higher temperature $\left(100^{\circ} \mathrm{C}\right)$ improved the rate of evaporation, but it was not possible to achieve a 187 complete regeneration of the solution after $4 \mathrm{~h}$. In order to understand why the regeneration was so 188 difficult, one has to focus on the fact that ammonia is not present as a free compound but as a copper 189 complex. Pavelka et al. [15] have studied the relation between the structures of $\mathrm{Cu}(\mathrm{I}) / \mathrm{Cu}(\mathrm{II}) \mathrm{cations}$ and 190 various ammonia-water environments. According to Pavelka et al., the sterically corrected stabilization 191 energy of the $\left[\mathrm{Cu}\left(\mathrm{NH}_{3}\right)_{4}\right]^{2+}$ complex is $391.8 \mathrm{kcal} \mathrm{mol}^{-1}$, against the $321.1 \mathrm{kcal} \mathrm{mol}^{-1}$ of the $\left[\mathrm{Cu}\left(\mathrm{H}_{2} \mathrm{O}\right)_{4}\right]^{2+}$ water 192 complex. This means that in a water solution containing ammonia and copper, the natural state of copper 193 is within the ammonia complex. This fact is also supported by the high complex formation equilibrium $K_{f}$ 194 constant for the following [16]: 
196 where

$197 K_{f}=\frac{\left[\left[\mathrm{Cu}\left(\mathrm{NH}_{3}\right)_{4}\right]^{2+}\right]}{\left[\mathrm{Cu}^{2+}\right]\left[\mathrm{NH}_{3}\right]^{4}}$

198 The very high value of $K_{f}$ underlines a very unbalanced equilibrium toward the products, which results in 199 the difficult regeneration of the solution.

\subsubsection{Effect of various operative parameters}

202 In order to accelerate and increase the regeneration of ammonia, a set of experiments was performed 203 under different operating conditions. First, some preliminary tests were performed for a longer duration 204 (5 hours) with a lower initial concentration of the ammonia complex (close to $65 \mathrm{mM}$ ) at $60^{\circ} \mathrm{C}$. As shown 205 in fig. 2, a very slow removal occurred. Hence, various approaches were used to accelerate the 206 evaporation, including stripping with air (by imposing an air flow pulled by a vacuum pump), the addition 207 of a bed of glass balls and an increased temperature up to $100^{\circ} \mathrm{C}$. Both the stripping and the utilization of 208 glass balls had a positive effect (fig. 3), but they did not achieve the total regeneration at $60{ }^{\circ} \mathrm{C}$, thus 209 showing that this temperature is not sufficient for the regeneration step. Conversely, the utilization of the 210 very same setup at the higher temperatures of $90{ }^{\circ} \mathrm{C}$ and $100{ }^{\circ} \mathrm{C}$ allowed an almost total removal of 211 ammonia, with only $8 \mathrm{mM}$ and $4 \mathrm{mM}$ remaining, respectively.

213 It was reported in the literature that the addition of nitric acid was required in order to gain full solution 214 regeneration [6]. To evaluate the effect of the addition of an acid to the solution on the efficiency of the 215 regeneration process, some tests were performed adding $3.89 \mathrm{~mL}$ and $7.75 \mathrm{~mL}$ of a water solution 216 containing $\mathrm{HNO}_{3}$ to $100 \mathrm{~mL}$ of the ammonia complex solution $(\mathrm{pH} 9.6)$, giving a $\mathrm{pH}$ of 6.4 and 9, 
217 respectively. After the first hour of treatment, the residual concentration of the complex was quite similar

218 for all the samples tested, regardless of the initial pH (see Table 4). In this case, UV-VIS absorbance was

219 used to estimate regeneration according to Table 1. Furthermore, overall durations of the tests were in

220 line with the previous results, indicating that the addition of the acid was not necessary under adopted

221 operating conditions.

222

\begin{tabular}{|c|c|c|c|}
\hline \multicolumn{4}{|c|}{$\mathrm{Cu}\left(\mathrm{NH}_{3}\right)_{4}{ }^{2+}$ molar concentration } \\
\hline \multirow{2}{*}{$\begin{array}{c}t \\
\text { (hours) } \\
\end{array}$} & \multicolumn{3}{|c|}{ Initial $p H$} \\
\hline & 6.4 & 9 & 9.6 \\
\hline 0 & 0.030 & 0.170 & 0.327 \\
\hline 1 & 0.015 & 0.014 & 0.010 \\
\hline 2 & 0.012 & 0.009 & 0.009 \\
\hline 3 & 0.007 & 0.007 & 0.008 \\
\hline 4 & 0.008 & 0.004 & 0.005 \\
\hline 5 & 0.006 & 0.003 & 0.004 \\
\hline \multicolumn{4}{|c|}{$\begin{array}{l}\text { Table 4: Effect of } \mathrm{pH} \text { correction on residual complex } \\
\text { concentration during regeneration at the temperatures of } \\
100^{\circ} \mathrm{C} \text { using a glass balls bed and stripping flux. } \mathrm{HNO}_{3} \text { was } \\
\text { added to reduce the } \mathrm{pH} \text { from the original } 9.55 \text { to } 9.04 \text { and } \\
\text { finally to 6.43. Data reported in this table was achieved using } \\
\text { the calibration line obtained with absorbance instead of pH. }\end{array}$} \\
\hline
\end{tabular}

226 In order to verify the effectiveness of the regeneration step, various cycles of energy

227 production/regeneration were carried out according to the results reported in paragraph 3.1; for the 228 power production stage, the cathodic and anodic solutions presented the following components:

$229-$ Cathode: $5 \mathrm{M} \mathrm{NH}_{4}\left(\mathrm{NO}_{3}\right)$ and $0.1 \mathrm{M} \mathrm{Cu}\left(\mathrm{NO}_{3}\right)_{2}$;

230 Anode: $5 \mathrm{M} \mathrm{NH}_{4}\left(\mathrm{NO}_{3}\right)$ and $0.1 \mathrm{M} \mathrm{Cu}\left(\mathrm{NO}_{3}\right)_{2}$ along with $3 \mathrm{M} \mathrm{NH}_{3}$ for the anolyte. 
231 For the regeneration step, the solution was performed at $100^{\circ} \mathrm{C}$ using a stripping flow and a glass balls

232 bed, with the exception of the last stage which was operated at $90{ }^{\circ} \mathrm{C}$. Energy discharge through a $3 \Omega$

233 external resistor was measured against time and reported as power density in fig. 4.

234 A maximum power density of $30.7 \mathrm{~W} \mathrm{~m}^{-2}$ was observed for the first cycle, corresponding to a current 235 density of $252.9 \mathrm{~A} \mathrm{~m}^{-2}$, which was more than that obtained during polarization (see fig. 1). The production 236 cycle was divided into two steps, the first characterized by high power densities and the second part by a 237 steep decrease to a tenth of these values. The duration of the initial step was found to be approximately 238 ten minutes for the adopted setup, after which power production was more stable. At the end of the first 239 cycle, the anodic solution was regenerated as detailed above. The exhausted anolyte, after regeneration, 240 was used as the catholyte. Energy production started again, regardless to whether the initial values were 241 lower when compared to the first cycle (see fig. 4). At the end of the second cycle, both the anodic and 242 cathodic solutions were regenerated: the catholyte of the second cycle was supplemented with an 243 equivalent amount of ammonia evaporated from the anolyte, obtaining the new catholyte. In this case, 244 the highest power density of $33.45 \mathrm{~W} \mathrm{~m}^{-2}$ was achieved, corresponding to $263.97 \mathrm{~A} \mathrm{~m}^{-2}$, and $89.20 \mathrm{~W} \mathrm{~m}^{-3}$. 245 The same procedure was repeated for the third time and also resulted in successful regeneration and 246 power production. For the last regeneration, a lower temperature of $90^{\circ} \mathrm{C}$ was used which resulted in 247 small power losses when compared to the power generation cycle implemented after any of the 248 regenerations at $100^{\circ} \mathrm{C}$. However, the use of a lower temperature would be advantageous from an 249 industrial perspective. Hence, it is possible to conclude that the proposed regeneration strategy allows 250 the TRAB process to be carried out effectively.

253 Thermally regenerative electrochemical cycles are recognized to be fundamental tools for the harvesting 254 of low-grade energy such as waste heat coming from industrial or natural sources. Amongst the others, 
TRAB is characterized by very high values of power density and a relatively simple setup. While much work

256 was already done in order to optimize the parameters governing the energy generation phase, little

257 attention was given to the regeneration step. For this reason, in this work, a systematic study of

258 regeneration apparatus was given, along with optimal operative parameters to be used during this phase.

259 The preliminary investigation of the generation stage was focused to evaluate the effect of various

260 operative parameters including the solution composition, hydrodynamic regime and $\mathrm{pH}$. In particular,

261 there was a substantial benefit in using a more basic $\mathrm{pH}$ of 10.5 compared to the naturally occurring $\mathrm{pH}$

262 of 9.5. Furthermore, within instrumental limits (700 rpm), increasing mass transport increased power

263 density up to $37 \mathrm{~W} \mathrm{~m}^{-2}$. When the attention was focused on the regeneration step, a major dependency

264 on temperature was found to exist as it was not possible to achieve a complete regeneration at

265 temperatures below $90^{\circ} \mathrm{C}$. Nevertheless, even at the highest temperature of $100^{\circ} \mathrm{C}$ here exploited, an

266 effective regeneration was not achieved until the regeneration apparatus was modified to include a

267 sustained air stripping-flow and a glass balls bed to enhance the gas phase-transition of ammonia. Finally,

268 a conventional TRAB for five successive generation/regeneration cycles avoiding the usage of fresh

269 solutions was operated successfully.

271 Acknowledgement

272 This study was supported by the European Commission through the project H2020-LCE-2014-1-640667 -

273 Conversion of Low Grade Heat to Power through closed loop Reverse Electro-Dialysis (RED-Heat-to-

274 Power). Authors would like to thank Miss Urvi Patel for help proofreading the manuscript.

275 Compliance with Ethical Standards

276 The authors declare that they have no conflict of interest.

277 References

278 1. Crutzen PJ (2002) Geology of mankind. Nature 415:23-23 . doi: 10.1038/415023a

279 2. Wagreich M, Draganits E (2018) Early mining and smelting lead anomalies in geological archives 
as potential stratigraphic markers for the base of an early Anthropocene. Anthr Rev 2053019618756682 . doi: 10.1177/2053019618756682

282

283

3. Gao C, Lee SW, Yang Y (2017) Thermally Regenerative Electrochemical Cycle for Low-Grade Heat Harvesting. ACS Energy Lett 2:2326-2334 . doi: 10.1021/acsenergylett.7b00568

4. Panayiotou GP, Bianchi G, Georgiou G, et al (2017) Preliminary assessment of waste heat potential in major European industries. Energy Procedia 123:335-345 . doi: 10.1016/j.egypro.2017.07.263

5. Chum HL, Osteryoung RA (1980) Review of Thermally Regenerative Electrochemical Systems. Rep SERI/TR- 332416, 1:

6. Zhang F, Liu J, Yang W, Logan BE (2015) A thermally regenerative ammonia-based battery for efficient harvesting of low-grade thermal energy as electrical power. Energy Environ Sci 8:343349. doi: 10.1039/C4EE02824D

7. Zhang F, LaBarge N, Yang W, et al (2015) Enhancing Low-Grade Thermal Energy Recovery in a Thermally Regenerative Ammonia Battery Using Elevated Temperatures. ChemSusChem 8:10431048 . doi: $10.1002 /$ cssc. 201403290

8. Rahimi M, Angelo AD, Gorski CA, et al (2017) Electrical power production from low-grade waste heat using a thermally regenerative ethylenediamine battery. J Power Sources 351:45-50 . doi: 10.1016/j.jpowsour.2017.03.074

9. Rahimi M, Kim T, Gorski CA, Logan BE (2018) A thermally regenerative ammonia battery with carbon-silver electrodes for converting low-grade waste heat to electricity. J Power Sources 373:95-102 . doi: 10.1016/j.jpowsour.2017.10.089

10. Zhu X, Rahimi M, Gorski CA, Logan B (2016) A Thermally-Regenerative Ammonia-Based Flow Battery for Electrical Energy Recovery from Waste Heat. ChemSusChem 9:873-879 . doi: $10.1002 /$ cssc. 201501513

11. Rahimi M, Zhu L, Kowalski KL, et al (2017) Improved electrical power production of thermally regenerative batteries using a poly ( phenylene oxide ) based anion exchange membrane. J Power Sources 342:956-963 . doi: 10.1016/j.jpowsour.2017.01.003

12. Rahimi M, Schoener Z, Zhu X, et al (2017) Removal of copper from water using a thermally regenerative electrodeposition battery. J Hazard Mater 322:551-556 . doi: 10.1016/j.jhazmat.2016.10.022

13. Vazquez-Arenas J, Lazaro I, Cruz R (2007) Electrochemical study of binary and ternary copper complexes in ammonia-chloride medium. Electrochim Acta 52:6106-6117 . doi: 10.1016/j.electacta.2007.03.062

14. Wagman DD, Evans WH, Parker VB, et al (1969) Selected values of chemical thermodynamic properties : Tables for Elements 35 Through 53 in the Standard Order of Arrangement. Washington, D.C. 20234

15. Pavelka M, Burda J V. (2005) Theoretical description of copper $\mathrm{Cu}(\mathrm{I}) / \mathrm{Cu}(\mathrm{II})$ complexes in mixed ammine-aqua environment. DFT and ab initio quantum chemical study. Chem Phys 312:193-204 . doi: 10.1016/j.chemphys.2004.11.034 
319 16. Dean JA (1990) LANGE'S HANDBOOK OF CHEMISTRY. Mater Manuf Process 5:687-688 . doi: $320 \quad 10.1080 / 10426919008953291$

321

322 


\section{$323 \quad$ Figure captions}

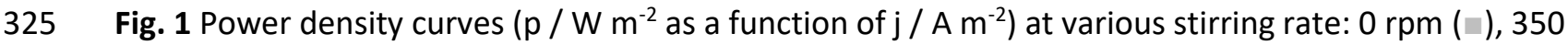

$326 \mathrm{rpm}(\triangle)$ and $700 \mathrm{rpm}(\bullet) . \mathrm{NH}_{4}\left(\mathrm{NO}_{3}\right) 5 \mathrm{M}$ and $\mathrm{Cu}\left(\mathrm{NO}_{3}\right)_{2} 0.1 \mathrm{M}$ for both anodic and cathodic solutions, 2

$327 \mathrm{M}$ of $\mathrm{NH}_{3}$ were also added in the anodic solution.

328

329 Fig. 2 Preliminary regeneration tests at the temperatures of $60^{\circ} \mathrm{C}$ (grey triangle, $\Delta$ ) and $100^{\circ} \mathrm{C}$ (black

330 circle, $\bullet$ )

331

332

Fig. 3 Regeneration test substituting the distillation balloon with a column. a) At the lower temperature of $60^{\circ} \mathrm{C}$, from the basic operation just heating (dark grey circle, $\bullet$ ), complex dissociation was increased adding a stripping flow (light grey circle, ${ }^{\circ}$ ) and then filling the column with a bed of glass balls (black

335 circle, $\bullet$ ). Last experiments were performed at the higher temperatures of $90^{\circ} \mathrm{C}$ (black X) and $100^{\circ} \mathrm{C}$

336 (black $\boldsymbol{\Delta}$ ) were then applied to the complete system. b) A visual comparison of the starting, complex-

337 saturated, solution with the resulting regenerated one.

Fig. 4 Current density production in time during 5 successive cycles. After the first cycle the anodic solution was regenerated and used as cathodic during the second. In the third cycle, the solution was

341 supplemented with new ammonium hydroxide and reused as anodic, along with the regenerated

342 solution of the second cycle used as cathodic. Last cycle regeneration was accomplished at $90^{\circ} \mathrm{C}$ for 5 343 hours. 


\section{On the regeneration of thermally regenerative ammonia batteries \\ Journal of Applied Electrochemistry}

Fabrizio Vicaria , Adriana D’Angelo ${ }^{a}$, Yohan Kouko ${ }^{b}$, Alessandro Loffredia ${ }^{a}$ Alessandro Galia ${ }^{a}$, Onofrio Scialdone ${ }^{a^{*}}$

aDepartment of Innovation, Industrial and Digital (DIID, Ingegneria Chimica, Gestionale, Informatica, Meccanica), Università degli Studi di

Palermo, 90128 Palermo, Italy.

bDepartment of Chemistry, Faculty of Sciences Jean Perrin University of Artois -, Rue Jean Souvraz, 62300 LENS.

*corresponding authors: onofrio.scialdone@unipa.it, +39 09123863754 
Figure 1

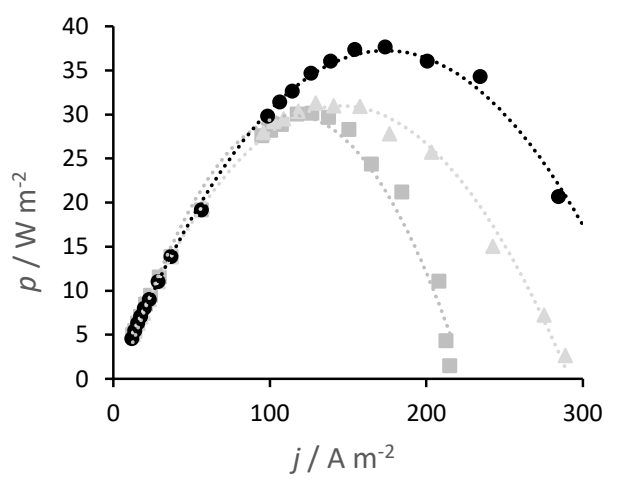


Figure 2

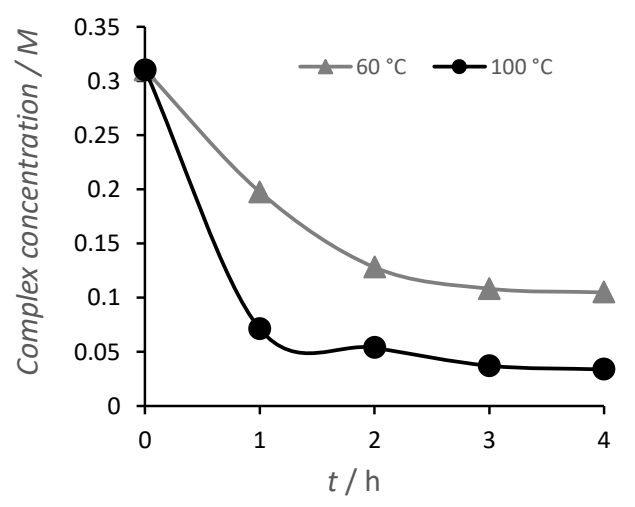




\section{Figure 3}

a)

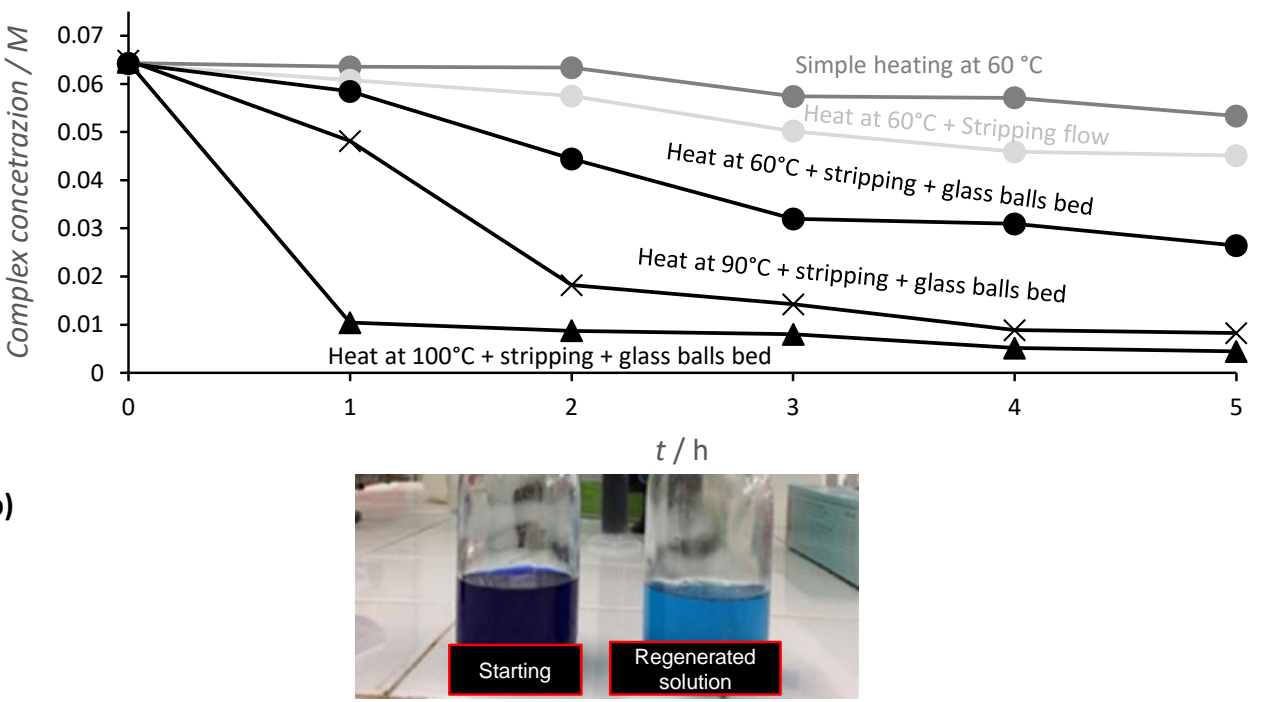


Figure 4

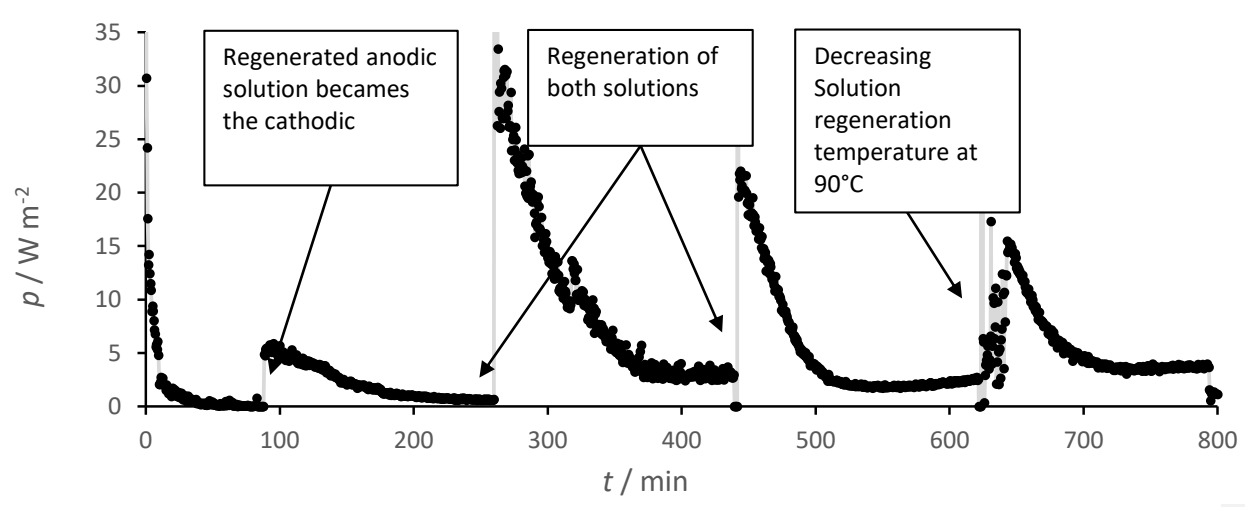

5 